\title{
Progressive osseous heteroplasia: diagnosis, treatment, and prognosis
}

\author{
This article was published in the following Dove Press journal: \\ The Application of Clinical Genetics \\ 30 January 2015 \\ Number of times this article has been viewed
}

\author{
Robert J Pignolo ${ }^{1-3}$ \\ Girish Ramaswamy ${ }^{2,3}$ \\ John T Fong ${ }^{2,3}$ \\ Eileen M Shore ${ }^{2-4}$ \\ Frederick S Kaplan ${ }^{1-3}$ \\ 'Department of Medicine, \\ ${ }^{2}$ Department of Orthopaedic Surgery, \\ ${ }^{3}$ The Center for Research in FOP and \\ Related Disorders, ${ }^{4}$ Department of \\ Genetics, University of Pennsylvania \\ Perelman School of Medicine, \\ Philadelphia, PA, USA
}

\begin{abstract}
Progressive osseous heteroplasia $(\mathrm{POH})$ is an ultrarare genetic condition of progressive ectopic ossification. Most cases of $\mathrm{POH}$ are caused by heterozygous inactivating mutations of $G N A S$, the gene encoding the alpha subunit of the G-stimulatory protein of adenylyl cyclase. $\mathrm{POH}$ is part of a spectrum of related genetic disorders, including Albright hereditary osteodystrophy, pseudohypoparathyroidism, and primary osteoma cutis, that share common features of superficial ossification and association with inactivating mutations of GNAS. The genetics, diagnostic criteria, supporting clinical features, current management, and prognosis of $\mathrm{POH}$ are reviewed here, and emerging therapeutic strategies are discussed.
\end{abstract}

Keywords: progressive osseous heteroplasia, GNAS, heterotopic ossification

\section{Introduction}

Progressive osseous heteroplasia $(\mathrm{POH})$ is an ultrarare genetic condition of progressive extraskeletal bone formation (Online Mendelian Inheritance in Man 166350). ${ }^{1}$ $\mathrm{POH}$ is clinically suspected by cutaneous ossification, usually presenting in early life, that involves subcutaneous and then subsequently deep connective tissues, including muscle and fascia. Most cases of $\mathrm{POH}$ are caused by heterozygous inactivating mutations of $G N A S$, the gene encoding the alpha subunit of the G-stimulatory protein of adenylyl cyclase $(\mathrm{Gs} \alpha){ }^{2} \mathrm{POH}$ is among a number of related genetic disorders, including Albright hereditary dystrophy (AHO), pseudohypoparathyroidism (PHP), and primary osteoma cutis (OC), that share common features of superficial heterotopic ossification (HO) in association with inactivating mutations of $G N A S .^{3-5}$ Although there are similarities among these conditions, $\mathrm{POH}$ is distinguished clinically from these related disorders by the deep and progressive nature of the heterotopic bone that forms in $\mathrm{POH} .{ }^{6}$ Clinically, $\mathrm{POH}$ overlap syndromes are recognized in which both POH-like HO and features of AHO or PHP are present. Most cases of POH, PHP1a (pseudohypoparathyroidism type 1a), and AHO are associated with heterozygous inactivating mutations of the GNAS gene, which is transcriptionally regulated through multiple promoters and the production of several transcripts, both protein-coding and noncoding RNAs. ${ }^{7,8}$ The major product of the locus is the G-protein subunit Gs $\alpha$. Additional regulatory complexity of the GNAS locus results from genomic imprinting, which causes allele-specific regulation of transcript expression that influences the spectrum of clinical phenotypes of the GNAS inactivation disorders. ${ }^{2,9-31}$ 


\section{GNAS function, genetics, regulation, and signaling \\ G-protein repertoire and signaling}

Guanine nucleotide-binding proteins (G-proteins) are ubiquitous and mediate key extracellular signals that transmit autocrine, paracrine, and endocrine signals. G-proteins are heterotrimeric complexes of $\alpha, \beta$, and $\gamma$ subunits. At this time, $21 \mathrm{G} \alpha$ subunits encoded by 16 genes are classified into four families on the basis of their $\alpha$-subunit component: $G_{s}$, $\mathrm{G}_{\mathrm{i} / \mathrm{o}}, \mathrm{G}_{\mathrm{q} / 11}$, and $\mathrm{G}_{12 / 1 / 1}$. In addition, six $\mathrm{G} \beta$ subunits encoded by five genes and twelve $\mathrm{G} \gamma$ subunits are recognized. Ligands, including hormones (eg, parathyroid [PTH]), neurotransmitters (eg, acetylcholine), and chemokines (eg, CXC chemokines), activate seven-transmembrane domain G-protein coupled receptors (GPCRs; such as the PTH receptor and the $\beta$-adrenergic receptor); more than 1,000 GPCRs have been identified in the mammalian genome. ${ }^{32-34}$

A given GPCR binds and interacts with only a subset of G-protein $\alpha$-subunits, with specificity conferred by different structural motifs of both the receptor and the G-protein. ${ }^{33,35}$ On ligand binding, activated GPCRs function as guanine nucleotide exchange factors, causing the release of guanosine diphosphate (GDP) and binding of guanosine triphosphate (GTP) to the G $\alpha$ subunit. This GDP-GTP switch leads to a conformational change in the G-protein $\alpha$-subunit and promotes the release of $\mathrm{G} \alpha$ and $\mathrm{G} \beta \gamma$ subunits from the heterotrimeric complex. Gs $\alpha$-GTP activates adenylyl cyclase to convert adenosine triphosphate to cyclic adenosine monophosphate (cAMP), an important secondary messenger that regulates multiple cellular processes. The inherent GTPase activity of the G $\alpha$ subunit subsequently stimulates GTP hydrolysis and GDP binding, followed by reassociation of the $\alpha$ subunit with the $\beta \gamma$ subunits and by return to the basal state.

The duration of G-protein activation and signaling is regulated by the GTPase activity intrinsic to the G $\alpha$ subunit. The GTPase reaction is catalyzed by a family of proteins called "regulators of G-protein signaling" (RGS). RGS proteins bind to $\mathrm{G} \alpha$ subunits to stabilize the transition state of and to accelerate GTP hydrolysis. RGS proteins serve as scaffolding proteins that coordinate components of GPCR signaling to orchestrate their rapid activation and termination. ${ }^{36}$ Thirty-seven RGS proteins, clustered into ten subfamilies, are currently known. Although various RGS proteins have been demonstrated to play roles in a broad range of metabolic processes, including lipolysis and cellular differentiation, some of them directly affect Gs $\alpha$ and downstream cAMP signaling. Specifically, RGS2 and RGS-Px1 have been identified to downregulate Gs $\alpha$-mediated cAMP signaling, whereas RGS4 impedes Gi- and Gq-mediated cAMP synthesis. ${ }^{37-39}$

\section{GNAS locus organization and genomic imprinting}

The GNAS gene is a highly complex locus that synthesizes several transcripts (Figure 1), the most abundant and best

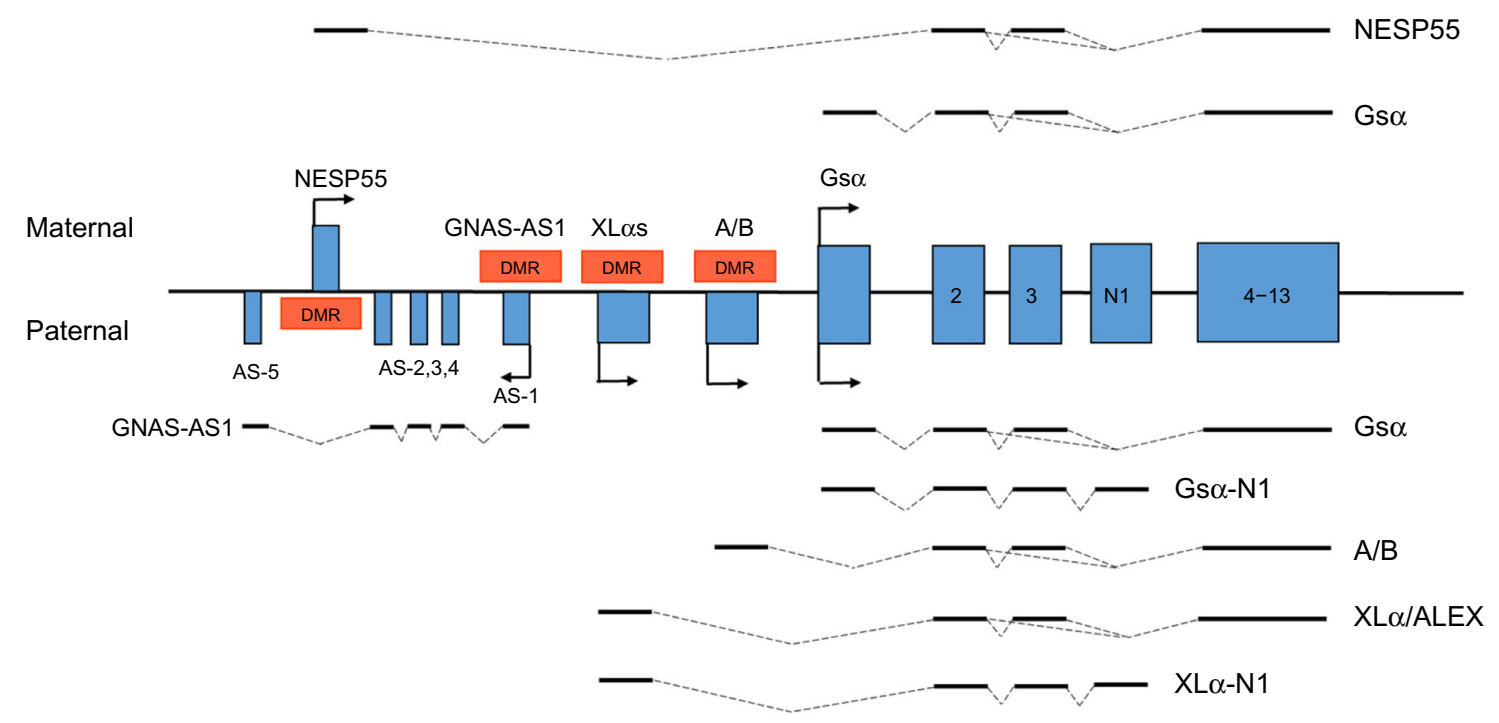

Figure I Schematic diagram of multiple transcripts from the GNAS locus.

Notes: Gs $\alpha$, XL $\alpha$ s, and NESP55 are the primary transcripts that produce proteins from the GNAS locus. GNAS-ASI is transcribed in the antisense direction. All transcripts have distinct first exons that splice to common exons 2-13. Gs $\alpha$ is biallelic in most tissues. XL $\alpha$ s, A/B, and GNAS-ASI are restricted to expression from the paternal allele, whereas NESP55 is only expressed maternally. Imprinting is regulated by differentially methylated regions (DMR) in the promoters. Alternative splicing leads to neuronalspecific transcripts Gs $\alpha-\mathrm{NI}$ and XL $\alpha$ s-NI, whereas a second open reading frame of XLos leads to a protein called ALEX. Transcripts from maternal and paternal alleles are shown above and below, respectively. Bold lines indicate exons, and dashed lines indicate introns. 
characterized of which encodes the ubiquitously expressed $\alpha$-subunit of the stimulatory $\mathrm{G}$ protein $(\mathrm{Gs} \alpha)$. Other proteincoding transcripts produce XL $\alpha$, the extra-large variant of Gs $\alpha$ (Gnasxl in mice), and NESP55, a neuroendocrine secretory protein (mouse Nesp)..$^{3,40,41}$ Each of the GNAS transcripts are initiated at unique promoters and first exons but share common downstream exons (exons 2-13 in humans and 2-12 in mice) of the GNAS locus (Figure 1). Alternative splicing of exon 3 generates short and long forms of both Gs $\alpha$ and XLos, and neuronal-specific splicing to include exon N1, which resides between exons 3 and 4, leads to the Gs $\alpha-\mathrm{N} 1$ and XLos-N1 transcripts that have a truncated $\mathrm{C}$ terminus. A second open reading frame of XL $\alpha$ s mRNA produces a protein called ALEX that is unrelated to G-proteins. In addition, the transcripts $\mathrm{A} / \mathrm{B}$ (mouse exon 1A) and GNAS antisense (human GNAS-AS1 or mouse Nespas) appear to be non-protein-coding transcripts, although translation of $\mathrm{A} / \mathrm{B}$ is predicted to start at an in-frame ATG start site within exon 2 and to produce a truncated Gs $\alpha$ isoform. ${ }^{3,40-43}$

The GNAS locus also exhibits genomic imprinting, adding yet another level of regulatory complexity. ${ }^{3,40,41,44,45}$ Allele-specific expression of GNAS transcripts is dependent on parent of origin, resulting in transcript expression from only one allele. The effects of preferential expression of one of the two GNAS alleles are reflected in the different disease phenotypes that result from GNAS inactivation of paternally versus maternally inherited genes. For example, PHP1a is primarily caused by maternally inherited heterozygous mutations in GNAS locus, whereas $\mathrm{POH}$ is correlated with inactivating mutations in the paternally inherited allele.

$\mathrm{XL} \alpha$ s and $\mathrm{A} / \mathrm{B}$ transcripts are expressed only from the paternally inherited GNAS gene copy, whereas NESP55 is synthesized only from the maternally inherited allele. In contrast, Gs $\alpha$ is expressed biallelically in most tissues, including bone and white adipose tissue. However, Gso transcription is regulated by tissue-specific imprinting and is restricted to expression from the maternal allele in tissues including renal proximal tubules, thyroid, pituitary, and gonads. ${ }^{3,40,41,44,45}$

Various functions have been attributed to GNAS transcripts on the basis of phenotypes in mice with specific deletions. Mice that are null for Gs $\alpha$ are embryonic lethal, whereas heterozygotes show different metabolic and tissue-specific phenotypes according to parent of origin of the mutation. Similar to PHP patients, mice with maternal inheritance of exon 1 mutations that decrease Gs $\alpha$ and cAMP levels exhibit resistance to PTH and thyroid stimulating hormone. ${ }^{46,47}$ Turan et al found that paternal silencing of Gs $\alpha$ in renal proximal tubules does not occur until after the early postnatal period, which could explain the development of PTH resistance and hypocalcemia only after infancy. ${ }^{48}$ Maternal allele GNAS inactivation is also expected to affect NESP55 expression. Plagge et al generated mice that are deficient in Nesp, which showed enhanced reactivity to novel environments appropriate for the protein's predominant expression in the central nervous system. ${ }^{49}$ XL $\alpha$, which shares sequence and functional similarity with Gs $\alpha$ at a protein level, forms heterotrimers with $G \beta \gamma$ subunits and activates adenylyl cyclase in specific cell types, similar to Gs $\alpha .{ }^{3,40}$ In addition, based on phenotypic observations from mouse models and data from newborn children, XLos has been known to play important functions during perinatal and early postnatal development. ${ }^{50}$ A summary of other mouse models that resemble human conditions of GNAS mutations has been provided elsewhere. ${ }^{8}$

\section{GNAS regulation of cellular differentiation via $\mathrm{CAMP} /$ protein kinase $\mathrm{A}$ (PKA) activation}

Gs $\alpha$ activation, through coupling to various receptors and ligands (PTH, adrenaline, glucagon, adenosine, etc) governs multiple important cellular processes to maintain physiologic functions and development in a variety of tissues. Gs $\alpha$ has been implicated in stem cell renewal ${ }^{51}$ and differentiation pathways, including osteogenesis, ${ }^{52,53}$ myogenesis, ${ }^{54}$ adipogenesis, ${ }^{55,56}$ chondrongenesis, ${ }^{57}$ and neurogenesis. ${ }^{58}$ In the context of $\mathrm{POH}$, in which ossifications occur within subcutaneous fat, a role of Gs $\alpha$ may be to maintain the balance in adipogenesis/osteogenesis in the mesenchymal stem cell (MSC) lineage. Although the molecular pathology of $\mathrm{POH}$ remains incompletely understood, substantial evidence shows that paternally inherited loss of Gs $\alpha$ function leads to subcutaneous $\mathrm{HO}$ and significant leaner phenotype in mice. ${ }^{55,59}$ Consistent with these observations, in vitro assays have shown that a paternally inherited Gs $\alpha$-inactivating mutation impairs adipogenesis and enhances osteogenesis in MSCs. ${ }^{52,53,55}$

In addition to the PTH receptor, other $\mathrm{G}$ protein-coupled receptors play roles in regulating the adipogenesis/ osteogenesis balance in MSCs, including the adenosine, $\beta$-adrenergic, and purinergic receptors. Studies using mouse preosteoblasts and rat bone marrow MSCs demonstrate that adenosine $\mathrm{A}_{2 \mathrm{~A}}$ receptors support adipogenic differentiation, whereas $A_{1}$ receptors play a role in the lipogenic activity of adipocytes. Conversely, $\mathrm{A}_{2 \mathrm{~B}}$ receptors inhibit adipogenesis and activate osteogenesis, illustrating the differential effects of adenosine receptors on MSC differentiation. ${ }^{60,61}$ The roles of beta-adrenergic receptors ( $\beta$-AR) in lipolysis and 
thermogenesis are well documented in vitro and in vivo. ${ }^{62}$ Moreover, studies have described $\beta 2$ - and $\beta 3$-AR as playing a part in regulating adipogenesis/osteogenesis partly via the cAMP/PKA pathway. Results from these studies indicate that antagonists of adrenergic receptors induce both adipogenesis and osteogenesis of mouse bone marrow MSCs. Similar to adenosine receptors, mRNA and protein expression of both $\beta 2$ - and $\beta 3$-AR are elevated during adipogenesis and osteogenesis in bone marrow-derived MSCs. Interestingly, $\beta 3-A R$ and $\beta 2-A R$ were found to be the dominant receptors in adipogenesis and osteogenesis, respectively. ${ }^{63,64}$ The purinergic receptor P2Y family also stimulates adenylyl cyclase activation and cAMP production ${ }^{65}$ and, additionally, have been implicated in white adipocyte physiology, including leptin secretion and lipolysis. ${ }^{66}$

\section{Signal transduction pathways downstream of GNAS and cAMP/PKA}

In $\mathrm{POH}, \mathrm{HO}$ initiates within subcutaneous fat before progressing to deep tissue, suggesting abnormal osteogenesis of mesenchymal precursor in adipose tissues. In fact, paternal inactivation of Gs $\alpha$ in adipose stromal cells (ASCs) enhances osteogenesis in vitro and promotes intramembranous $\mathrm{HO}$ in subcutaneous fat in vivo. ${ }^{52}$ Conversely, paternal-inactivation of Gs $\alpha$ in ASCs severely limits adipogenesis in vitro. ${ }^{55}$ Importantly, this defect can be rescued by an adenylyl cyclase activator (forskolin), ${ }^{55}$ indicating that Gs $\alpha$-cAMP signals regulate the bipotential adipogenic-osteogenic lineage cell fate switch.

Gs $\alpha$ expression is tightly regulated under physiologic and developmental conditions. Although Gs $\alpha$ signaling is ubiquitous, various cell types are expected to respond to G-protein signaling and cAMP in cell and developmentally specific manners. Gs $\alpha$ appears to have crucial roles in maintaining balance in two key signaling pathways: Wnt/ $\beta$-catenin and Hedgehog (Hh). ${ }^{67}$ Gain-of-function mutation of Gs $\alpha$ leads to overactive $\mathrm{Wnt} / \beta$-catenin signal and is associated with fibrous dysplasia, ${ }^{68}$ whereas loss-of-function mutations of Gs $\alpha$ lead to increased $\mathrm{Hh}$ signaling and are associated with $\mathrm{POH} .{ }^{67}$

Hh signaling controls numerous aspects of development, including proliferation, patterning, and morphogenesis. Three Hh proteins have been identified in vertebrates: Sonic (SHH), Indian, and Desert. Desert Hh expression is limited to the male reproductive tract, Indian $\mathrm{Hh}$ regulates chondrogenesis and endochondral bone formation, and $\mathrm{SHH}$ plays a critical role in the formation of the skeleton and in cell differentiation. ${ }^{69} \mathrm{SHH}$ signaling was also found to have antiadipogenic and pro-osteogenic effects in mouse ASCs
(mASCs) ${ }^{70}$ Hh signaling is activated when $\mathrm{Hh}$ protein binds to its receptor to relieve the protein smoothened (Smo) from its repressive state. Active Smo triggers a cascade of events that activates GLI transcription factors. Interestingly, $\mathrm{SHH}$ signaling enhances bone morphogenetic protein (BMP) 2 signaling (a known cytokine to be critical for osteogenesis) in mASCs. It is interesting to speculate that in $\mathrm{POH}$, loss of function of Gs $\alpha$ leading to enhanced Hh signaling would increase BMP signaling and contribute to $\mathrm{HO}$.

PKA (activated by cAMP) is known to negatively regulate Hh signaling by inhibiting GLI nuclear localization ${ }^{71}$ and targeting GLI for proteosomal degradation/truncation. ${ }^{72-74}$ Homozygous inactivation of GNAS in MSCs leads to overactivation of Hh signaling (observed in both in vitro and in vivo studies) and causes $\mathrm{POH}$-like $\mathrm{HO}$ in mice. ${ }^{67}$ Thus, elevation in Hh signaling in Gs $\alpha$-deficient cells appears to be the upstream signal that contributes to $\mathrm{HO}$ in $\mathrm{POH}$.

The BMP signal transduction pathway, a key regulator of osteoblast differentiation, serves to phosphorylate SMAD proteins and transcriptionally activate osteogenic genes. ${ }^{75,76}$ The relationship between GNAS and BMP signaling is not clear. However, using forskolin to stimulate cAMP production in mouse embryonic stem cells at the earliest stages of osteogenesis, Zhang et al demonstrated that BMP signaling and osteogenic markers (Msx2, Osterix) are significantly reduced, whereas adipogenic markers (LPL, PPARg, EBP1, aP2) are elevated. ${ }^{77}$ These findings provide further evidence that cAMP serves as a key regulator of osteoblast and adipocyte lineage commitment upstream of BMP signaling. ${ }^{77}$

\section{GNAS mutation in $\mathrm{POH}$ patients}

Heterozygous inactivating GNAS mutations occur in most patients with a definitive clinical diagnosis of $\mathrm{POH}$ (see following). All the POH-associated GNAS mutations identified in our cohort have mutations that cause a shift in the protein-coding reading frame: small deletions, insertions, duplications, or alteration of conserved splice site donor/ acceptor dinucleotides (Table 1). Nonsense mutations leading to early protein termination have not been identified in this cohort. Although some patients diagnosed with $\mathrm{AHO} /$ PHP1a have mutations in exon $1,{ }^{78}$ as do patients diagnosed with PHP1a/POH, we have not identified exon 1 mutations in patients with a confirmed diagnosis of $\mathrm{POH}$. Two $\mathrm{POH}$ patients with an exon 1 mutation have been reported; ${ }^{79}$ however, the clinical descriptions are ambiguous, and thus these diagnoses are not confirmed (see following for further discussion). Any functional significance for the absence of exon 1 mutations is unclear and could reflect the small sample 
Table I GNAS mutations in progressive osseous heteroplasia patients

\begin{tabular}{lll}
\hline $\begin{array}{l}\text { GNAS } \\
\text { location }\end{array}$ & Mutation site (cDNA) & $\begin{array}{l}\text { Frameshift } \\
\text { start (codon) }\end{array}$ \\
\hline Exon 5 & 344-345insT & 115 \\
Exon 5 & 348delC; & 116 \\
Exon 5 & 348-349insC & 117 \\
Exon 5 & 355delC & 119 \\
Exon 7 & 565-68delGACT & 189 \\
Exon 9 & 679-80insC & 227 \\
Exon 10 & 725delC & 242 \\
Exon 10 & 835-39dupIAACAG & 280 \\
Exon II & 860-6IdelTG & 287 \\
Exon II & 960insCT & 321 \\
Intron 12 & IVSI2+IG $>$ C splice donor site & 347 \\
Intron 12 & IVSI2-IG >C splice acceptor site & 347 \\
Exon 13 & I053-77dupI25n & 360 \\
Exon 13 & II07-08delTG & $369-370$ \\
Exon 13 & II62delC & 388 \\
\hline
\end{tabular}

size of $\mathrm{POH}$ patients. GNAS mutations in $\mathrm{POH}$ patients reduce Gs $\alpha$ protein levels and decrease cAMP signaling (our unpublished data).

Our unpublished data and other reports ${ }^{80}$ support that $\mathrm{POH}$ is preferentially caused by GNAS mutations occurring on the paternally inherited copy of the gene. This suggests that the paternal and maternal GNAS alleles function differently to regulate osteoblast differentiation (see earlier sections: GNAS regulation of cellular differentiation via cAMP/protein kinase A (PKA) activation and Signal transduction pathways downstream of GNAS and cAMP/PKA).

Classic mosaicism, or the presence of at least two genotypically different cell populations derived from a single zygote, may explain the pattern of lesion distribution in $\mathrm{POH}$ that distinguishes it from other $G N A S$-based conditions in which $\mathrm{HO}$ does not progress to deeper tissues. For example, a germline mutation in GNAS may be followed by a second mutation in the other allele during development and both be retained by a finite number of progenitor cells in the postnatal state. Possible mechanisms include the presence of somatic mutations or random inactivation of the second GNAS allele in progenitor cells, a de novo mutation in a gene that normally functions in a $G N A S$-interacting pathway, or epigenetic changes in somatic cells. Depending on the location of resident progenitor cells or their predisposition toward certain migration patterns, $\mathrm{HO}$ formation with progression to deeper tissues may be favored in POH. Revertant mosaicism in uninvolved dermomyotomes, or in patients with GNAS mutations and no apparent or very limited disease, cannot be excluded. ${ }^{81}$

Most $\mathrm{POH}$ mutations appear to be de novo mutations in a family, with a given specific mutation found in only a single family. ${ }^{6}$ However, a four-nucleotide deletion in exon 7 that was found to be a mutational hot spot for AHO/PHP1a is found as a recurring mutation in $\mathrm{POH}$ as well. Within a family, carriers with the mutation but no clinical manifestations have been identified.

\section{Clinical features and diagnosis}

As a disorder of extraskeletal bone formation, $\mathrm{POH}$ must first be differentiated from nonhereditary as well as other genetic conditions of HO to diagnose the condition (Table 2).

Table 2 Differential diagnosis of extraskeletal bone formation

Genetic

Primary osteoma cutis

Fibrodysplasia ossificans progressiva

Progressive osseous heteroplasia

Albright hereditary osteodystrophy

Pseudohypoparathyroidism Ia/lc (PHPIa/lc)

Progressive osseous heteroplasia overlap syndromes (POH/PHPIa/lc)

Nonhereditary

Injury

Traumatic head injury

Paraplegia/quadriplegia (spinal cord injury)

Poliomyelitis

Guillain-Barré syndrome

Muscle hematoma

Joint dislocation

After hip and knee arthroplasty

Surgical scars

Severe burns

Secondary osteoma cutis

Endovascular injury (atherosclerosis, valvular heart disease,

cerebrovascular accident)

Arthropathy

Ankylosing spondylitis

Psoriatic arthritis

Seronegative arthropathies

Diffuse idiopathic skeletal hyperostosis

Aging

Postarthroplasty

Atherosclerosis

Cerebrovascular accident

Valvular heart disease

Atherosclerosis

Miliary osteoma (of the face)*

Pressure ulcers ${ }^{\dagger, \neq}$

Urinary tract infections ${ }^{\ddagger}$

Other

Metastatic osteosarcoma

Fibrosing lung disorders

Pulmonary venous hypertension

Conditions that increase calcium-phosphate product levels

Notes: *Occurs predominantly in middle-aged and older females. ${ }^{\dagger} A t$ the site of reactive soft tissue ossification. $¥$ May be a predisposing factor or a secondary complication of nonhereditary heterotopic ossification.

Abbreviations: $\mathrm{AHO}$, Albright hereditary osteo dystrophy; $\mathrm{POH}$, progressive osseous heteroplasia; PHP, Pseudohypoparathyroidism. 
Nonhereditary forms of $\mathrm{HO}$ are excluded on the basis of prior trauma or surgery, age, and known history or suspicion of arthropathy. $\mathrm{POH}$ is distinguished from fibrodysplasia ossificans progressiva (FOP), another rare autosomal dominant genetic condition of $\mathrm{HO}$, by the presence of cutaneous ossification, the absence of congenital malformation of the first toes, and the absence of preosseous tumor-like inflammation or "flare-ups." 82,83 Other genetic causes of HO (Table 2) can be excluded on clinical grounds alone.

$\mathrm{POH}$ is among several related genetic disorders, including $\mathrm{AHO}$, PHP, and OC, which share the common features of superficial ossification and association with inactivating mutations of $G N A S .{ }^{4-6} \mathrm{AHO}$ is characterized by variable subsets of features, in addition to superficial HO, including short adult stature, obesity, round faces, brachydactyly, and neurobehavioral problems (including mental retardation). PHP, or end-organ resistance to PTH, is subdivided into types 1a, $1 \mathrm{~b}$, and $1 \mathrm{c} .{ }^{4}$ Clinically, PHP1a and $1 \mathrm{c}$ are identical and can include AHO features, deficient responses to PTH, and multiple other hormone resistance. PHP1a is distinguished from PHP1c by the presence of inactivating GNAS mutations and/or reduced activity of Gs $\alpha$, the major protein product encoded by the GNAS locus. Patients with PHP1b have hormone resistance, usually limited to PTH target tissues, but no AHO features or reduced Gs $\alpha$ activity. PHP1b is associated with a GNAS imprinting defect and caused by heterozygous deletions of a suspected imprinting control element in familial forms. ${ }^{4,14,45,84,85}$ Pseudopseudo-hypoparathyroidism (PPHP) refers to the condition in patients with $\mathrm{AHO}$ who do not have PTH resistance. OC describes superficial $\mathrm{HO}$ without any hormone resistance or AHO features. A familial form of primary OC has been described. ${ }^{86}$

$\mathrm{POH}$ is diagnosed on the basis of three major criteria: superficial HO that progresses to deep connective tissue; two or fewer AHO features, excluding $\mathrm{HO}$; and no $\mathrm{PTH}$ resistance (Table 3 ). Dermal involvement appears as hard maculopapular lesions (Figure 2A and B). Over time, these lesions coalesce into plaques with spread into deeper connective tissues including fascia, skeletal muscle, tendon, and ligament (Figure 2C). Small spicules of dermal bone may occasionally extrude through the epidermis, although bone formation does not originate in the epidermis. Extensive ossification of the deep connective tissues can result in ankylosis of affected joints and growth retardation of involved limbs (Figure 2C). ${ }^{1,87-90}$ In addition to $\mathrm{HO}$, some patients exhibit one or two AHO features, but never obesity or multiple AHO features. ${ }^{6}$ Hormonal abnormalities are rarely associated with $\mathrm{POH}$, and never PTH resistance. ${ }^{6}$
Table 3 Diagnostic criteria for progressive osseous heteroplasia

\begin{tabular}{l}
\hline Criteria \\
Major criteria \\
Superficial and deep heterotopic ossification \\
Two or fewer features of Albright hereditary dystrophy, not including \\
heterotopic ossification \\
No parathyroid hormone resistance \\
Supporting clinical findings \\
GNAS mutation \\
Evidence for paternal inheritance \\
Radiographic evidence for reticular pattern of ossification \\
Exclusive intramembraneous ossification or both intramembraneous \\
and endochondral ossification \\
Lateralization in a dermomyotomal pattern \\
History of intrauterine growth retardation \\
Leanness \\
Age of onset younger than I year
\end{tabular}

In addition to these key diagnostic criteria, there are several clinical findings that support the diagnosis of $\mathrm{POH}$ (Table 3). ${ }^{6}$ Although some individuals can present with a later age of onset, most $\mathrm{POH}$ patients have an average age of onset earlier than 1 year. Almost two-thirds of $\mathrm{POH}$ patients have mutations in GNAS. However, those without detectable mutations are clinically indistinguishable from those with mutations. Maternally inherited mutations in GNAS cause PHP1a, whereas paternally inherited mutations are associated with $\mathrm{POH}$ and are supportive of the diagnosis, especially with delayed onset of more extensive ossification. Although maternally inherited mutations are more often found with AHO, paternally inherited mutations can also be associated with AHO and lead to PPHP. POH-like HO associated with the overlap syndromes can be inherited through the maternal as well as the paternal allele. Although exon 1 mutations have been reported in individuals with subcutaneous ossifications (including those close to muscle) ${ }^{79}$ it is unclear whether these individuals meet the $\mathrm{POH}$ criterion of deep HO. In a large series of $\mathrm{POH}$ patients, diagnosed on the basis of key criteria described here only, exon 1 mutations were not found. ${ }^{6}$

Birth weight tends to be very low in patients with $\mathrm{POH}$, usually at or below the fifth percentile compared with sexmatched normative data. ${ }^{55}$ In fact, heterozygous GNAS mutations on either parental allele were found to be associated with intrauterine growth retardation, and when these mutations were located on the paternal GNAS allele, intrauterine growth retardation was considerably more pronounced compared with mutations on the maternal allele. ${ }^{50}$ At any age, $\mathrm{POH}$ patients with paternally inherited inactivating GNAS mutations were always found to have a lean phenotype. ${ }^{6,91}$ There is also a striking lateralization of lesions in a dermatomyotomal 


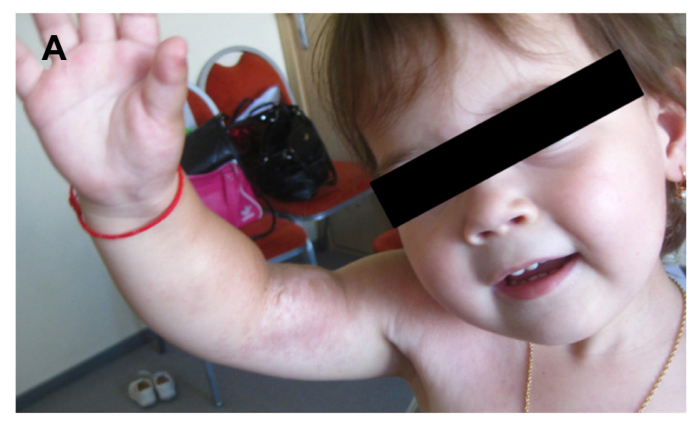

B

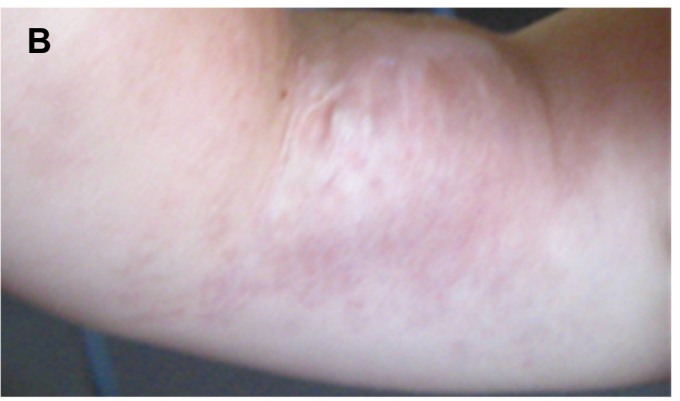

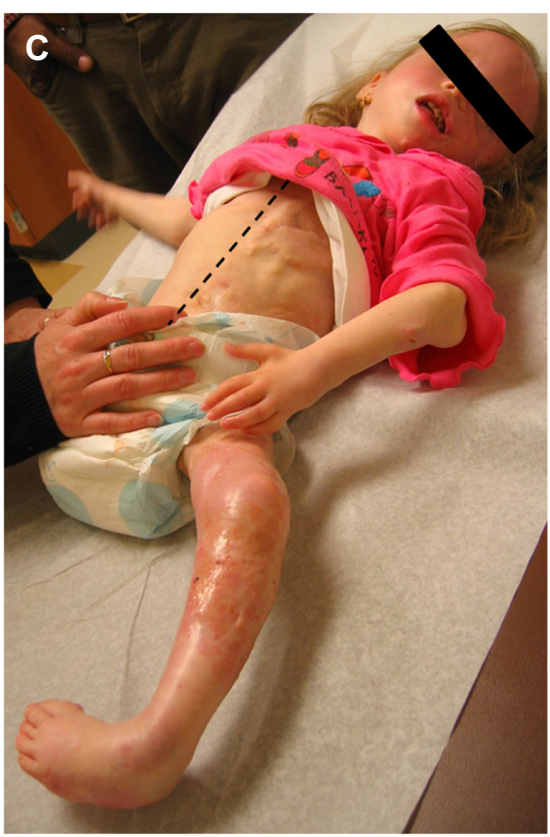

Figure 2 Appearance of heterotopic ossification in $\mathrm{POH}$.

Notes: (A and B) Early clinical appearance of heterotopic ossification in $\mathrm{POH}$. Note the maculopapular lesions that correspond to extensive dermal and subcutaneous ossification. (C) Advanced heterotopic ossification in $\mathrm{POH}$ results in large coalesced bony plaques. Note the distinct lateralization of lesions that is observed in some patients, as well as contracture and ankyloses of the left lower extremity.

Abbreviation: $\mathrm{POH}$, progressive osseous heteroplasia.

distribution (Figure 2C), ${ }^{81}$ but this may be difficult to assess early in the presentation. Radiographic appearance of $\mathrm{HO}$ in POH shows a distinctive reticular pattern of web-like ectopic bone involving soft connective tissues from the dermis down to skeletal muscle (Figure 3). Half of lesional biopsies taken in patients ultimately confirmed to have $\mathrm{POH}$ demonstrated intramembraneous ossification (Figure 4), with 20\% showing endochondral ossification and $30 \%$ both types. $^{6}$

POH occasionally presents as an overlap syndrome with additional features associated with other $G N A S$-based disorders of HO. Two cases in which patients exhibited progressive $\mathrm{HO}$ together with characteristics of AHO (short stature, round face, and brachydactyly) and reduced levels of Gs $\alpha$ protein were reported by Eddy et al:92 one of the two cases had a heterozygous $G N A S$ mutation. Another patient with progressive $\mathrm{HO}$ had severe plate-like OC and also possessed a mutation in the GNAS gene. ${ }^{93,94}$ These cases are consistent with $\mathrm{POH}$ being part of a clinical spectrum of $\mathrm{HO}$ disorders caused by inactivating GNAS mutations.

$\mathrm{POH}$, other disorders associated with inactivating mutations of GNAS, and $\mathrm{POH}$ overlap syndromes are distinguished solely by clinical criteria (Figure 5). GNAS-based disorders of $\mathrm{HO}$ can be divided into those presenting with stable superficial bony lesions and those in which superficial lesions progress into deep connective tissue. Among the nonprogressive forms are $\mathrm{OC}, \mathrm{AHO} / \mathrm{PPHP}$, and PHP1a/c.
Those without AHO features have OC. Those with AHO features and no hormone resistance have AHO/PPHP, and those with hormone resistance have PHP (Figure 5). The progressive types are $\mathrm{POH}$ and the $\mathrm{POH}$-related syndromes. Patients with $\mathrm{POH}$ present with superficial HO that progresses to deeper tissues in the absence of multiple other AHO features and without hormone resistance (Figure 5). A small subset of patients has progressive $\mathrm{HO}$ with more extensive AHO features ( $\mathrm{POH} / \mathrm{AHO})$ or with both $\mathrm{AHO}$ features and hormone resistance $(\mathrm{POH} / \mathrm{PHP} 1 \mathrm{a} / \mathrm{cc})$. It is possible that individuals without progressive $\mathrm{HO}$ could be too young at the time of initial diagnosis to have yet developed progressive disease. Similarly, individuals with $\mathrm{POH}$ could be too young at the time of diagnosis to have yet developed other features of AHO. Nevertheless, $\mathrm{POH}$ and progressive $\mathrm{HO}$ syndromes can be distinguished from other $G N A S$-based disorders by one clinical parameter alone: the extension of $\mathrm{HO}$ from superficial to deep tissue. GNAS inactivating mutations, either by presence alone or by mutation pattern within GNAS, do not predict a specific disorder, variability of phenotype, or severity of progression within this spectrum.

\section{Current management and prognosis}

In $\mathrm{POH}$, the degree of morbidity depends on the location and extent of $\mathrm{HO}$, and in some cases, the condition 

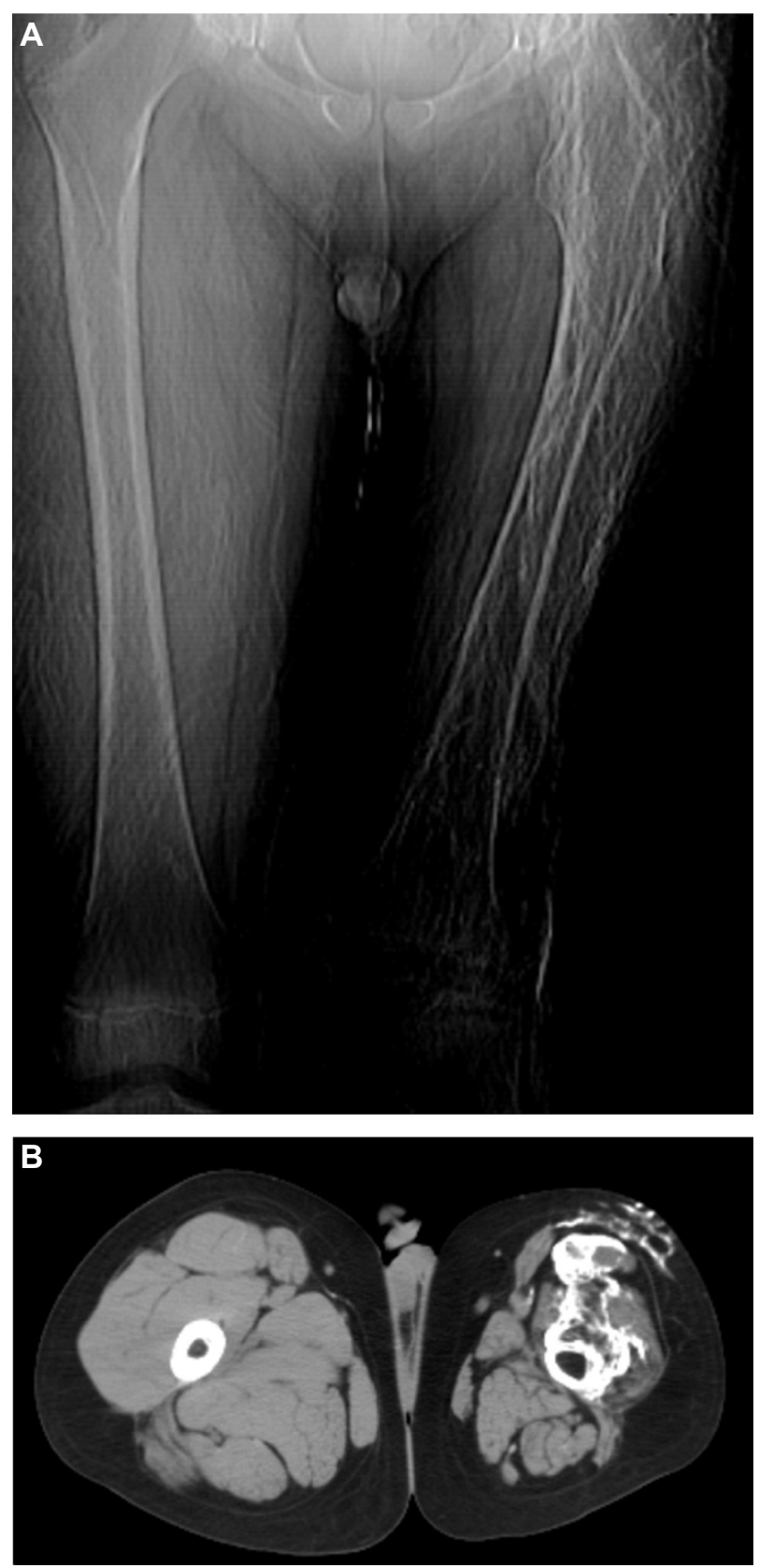

Figure 3 Radiographic appearance of severe heterotopic ossification in $\mathrm{POH}$. Notes: (A) Anterior view roentgenogram of the lower extremities of a child with $\mathrm{POH}$ shows progressive heterotopic ossification on the left side. Note the weblike pattern of ossification. (B) Cross-sectional, midfemur view by computerized tomography demonstrates extensive ossification of soft tissues in the superficial and deep posterior compartments of the leg.

Abbreviation: $\mathrm{POH}$, progressive osseous heteroplasia.

results in severe disability. ${ }^{1,93-95}$ Growth retardation may be associated with limited movement of extremities caused by joint ankyloses and bone pain, and secondary osteoporosis may ensue. . $^{1,93-95}$

Because of the ultrarare nature of $\mathrm{POH}$, we have limited information about prognosis. There are no distinguishing forms of $\mathrm{POH}$ based on progression; however, we did observe that $\mathrm{HO}$ in the dermis shows a seemingly random distribution

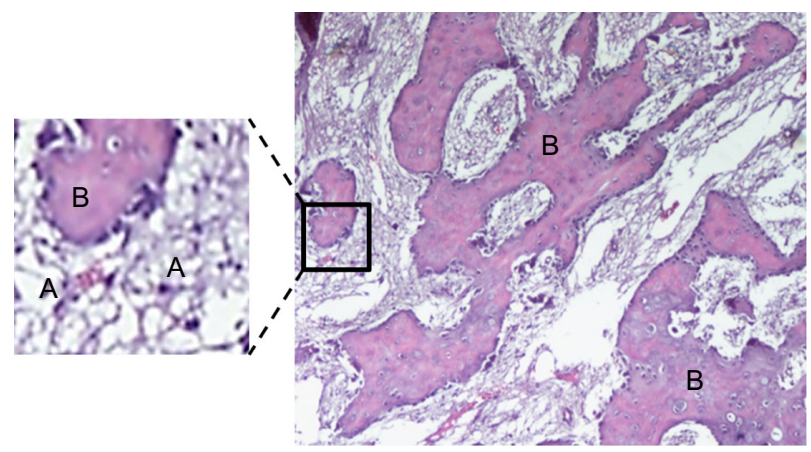

Figure 4 Photomicrograph of a $\mathrm{POH}$ lesional section shows intramembranous ossification.

Notes: Note that deposits of bone are surrounded by adipose tissue (inset). Hematoxylin and eosin staining; original magnification, 200x.

Abbreviation: $\mathrm{A}$, adipose tissue; $\mathrm{B}$, bone; $\mathrm{POH}$, progressive osseous heteroplasia.

of affected areas and that this mosaic distribution of lesions lateralized in a distinct dermomyotomal pattern present in very few conditions ${ }^{81}$ In some patients, dermomyotomal distribution was partial, which may suggest that lesion progression was incomplete or delayed at the time of presentation. Often it is only later in the course of the condition that one can clinically determine areas of severe involvement.

At this time, there are no effective treatments or prevention for POH. Surgical resection of diffuse lesions usually leads to recurrences or complications; ${ }^{1,2,82,87}$ however, areas of well-circumscribed $\mathrm{HO}$ can often be removed, with successful long-term results. ${ }^{94}$ Successful functional repositioning of a joint after the development of a contracture from $\mathrm{HO}$ was reported in the case of one child. ${ }^{88}$ Unfortunately, amputations are sometimes needed in the setting of severe growth retardation and functional ankylosis. ${ }^{89}$

A single case report on the use of the bisphosphonate pamidronate in $\mathrm{POH}$ suggested stabilization of the

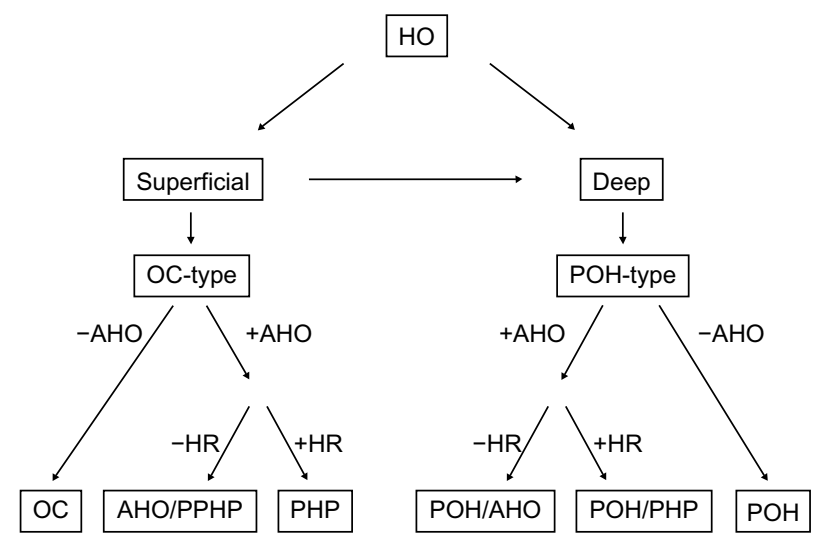

Figure 5 Diagnostic algorithm for distinguishing among GNAS-based conditions of heterotopic ossification.

Abbreviations: $\mathrm{HO}$, heterotopic ossification; $\mathrm{OC}$, osteoma cutis; $\mathrm{POH}$, progressive osseous heteroplasia; $\mathrm{AHO}$, Albright hereditary dystrophy; HR, hormone resistance; PPHP, pseudopseudo-hypoparathyroidism; PHP, pseudohypoparathyroidism. 
condition, ${ }^{96}$ but it is unclear how generally applicable this finding may be to prevention of new skin lesions. Treatment with bisphosphonate is unlikely to resolve preexisting bone formation in $\mathrm{POH}$.

Physical therapy and meticulous skin care are important conservative approaches to preserving movement and preventing cutaneous breakdown, respectively. ${ }^{90,95}$

\section{Emerging therapeutic strategies}

Regard et al showed that Gs $\alpha$ restricts bone formation to the normotopic skeleton by inhibiting Hh signaling in mesenchymal progenitor cells, whereas genetically mediated exogenous Hh signaling is sufficient to induce $\mathrm{POH}-$ like $\mathrm{HO} .{ }^{67}$ Furthermore, inhibition of this signaling pathway by genetic or pharmacological methods reduced the severity of ectopic bone formation. ${ }^{67}$ Therefore, Hh inhibitors currently used for other conditions, such as cancer, may be potential candidate drugs for treating $\mathrm{HO}$ caused by GNAS inactivation. ${ }^{97}$

Endochondral ossification is present singly or in combination with intramembranous ossification in $50 \%$ of $\mathrm{POH}$ lesional biopsies, ${ }^{6}$ and so known inhibitors of endochondral ossification are potential therapies. For example, retinoic acid receptor $\gamma$ agonists were shown to be highly effective at inhibiting $\mathrm{HO}$ in mouse models.$^{98} \mathrm{In}$ fact, a marked increase in Gs $\alpha$ expression at the transcriptional level is induced by retinoic acid, suggesting that the same retinoic acid receptor $\gamma$ agonists may be used to increase production of Gs $\alpha$ protein from the normal allele and minimize the effects of GNAS inactivation. ${ }^{99}$

\section{Acknowledgments}

We acknowledge Meiqi Xu for her excellent work in conducting the mutational sequence analyses presented in this article. This work was supported by the National Institutes of Health (R01-AR046831), the Progressive Osseous Heteroplasia Association, the Italian $\mathrm{POH}$ Association, the International Fibrodysplasia Ossificans Progressiva Association, the University of Pennsylvania Center for Research in FOP and Related Disorders, the Isaac and Rose Nassau Professorship of Orthopaedic Molecular Medicine (FSK), and the Cali/ Weldon Professorship (EMS).

\section{Disclosure}

The authors report no conflicts of interest in this work.

\section{References}

1. Kaplan FS, Craver R, MacEwen GD, et al. Progressive osseous heteroplasia: a distinct developmental disorder of heterotopic ossification. Two new case reports and follow-up of three previously reported cases. J Bone Joint Surg Am. 1994;76(3):425-436.
2. Shore EM, Ahn J, Jan de Beur S, et al. Paternally inherited inactivating mutations of the GNAS1 gene in progressive osseous heteroplasia. N Engl J Med. 2002;346(2):99-106.

3. Bastepe M. Relative functions of Gos and its extra-large variant XL $\alpha$ s in the endocrine system. Horm Metab Res. 2012;44(10): 732-740.

4. Bastepe M, Jüppner H. GNAS locus and pseudohypoparathyroidism. Horm Res. 2005;63(2):65-74.

5. Weinstein LS, Liu J, Sakamoto A, Xie T, Chen M. Minireview: GNAS: normal and abnormal functions. Endocrinology. 2004;145(12): 5459-5464.

6. Adegbite NS, Xu M, Kaplan FS, Shore EM, Pignolo RJ. Diagnostic and mutational spectrum of progressive osseous heteroplasia (POH) and other forms of GNAS-based heterotopic ossification. Am J Med Genet A. 2008;146A(14):1788-1796.

7. Thiele S, Werner R, Ahrens W, et al. Selective deficiency of Gsalpha and the possible role of alternative gene products of GNAS in Albright hereditary osteodystrophy and pseudohypoparathyroidism type Ia. Exp Clin Endocrinol Diabetes. 2010;118(2):127-132.

8. Turan S, Bastepe M. The GNAS complex locus and human diseases associated with loss-of-function mutations or epimutations within this imprinted gene. Horm Res Paediatr. 2013;80(4):229-241.

9. Ahmed SF, Dixon PH, Bonthron DT, et al. GNAS1 mutational analysis in pseudohypoparathyroidism. Clin Endocrinol (Oxf). 1998;49(4):525-531.

10. Ahrens W, Hiort O, Staedt P, Kirschner T, Marschke C, Kruse K. Analysis of the GNAS1 gene in Albright's hereditary osteodystrophy. $J$ Clin Endocrinol Metab. 2001;86(10):4630-4634.

11. Aldred MA, Trembath RC. Activating and inactivating mutations in the human GNAS1 gene. Hum Mutat. 2000;16(3):183-189.

12. Farfel Z, Iiri T, Shapira H, Roitman A, Mouallem M, Bourne HR. Pseudohypoparathyroidism, a novel mutation in the betagammacontact region of Gsalpha impairs receptor stimulation. J Biol Chem. 1996;271(33):19653-19655.

13. Fischer JA, Egert F, Werder E, Born W. An inherited mutation associated with functional deficiency of the alpha-subunit of the guanine nucleotidebinding protein Gs in pseudo- and pseudopseudohypoparathyroidism. J Clin Endocrinol Metab. 1998;83(3):935-938.

14. Jan De Beur SM, O'Connell JR, Peila R, et al. The pseudohypoparathyroidism type $\mathrm{lb}$ locus is linked to a region including GNAS1 at 20q13.3. J Bone Miner Res. 2003;18(3):424-433.

15. Linglart A, Carel JC, Garabédian M, Lé T, Mallet E, Kottler ML. GNAS1 lesions in pseudohypoparathyroidism Ia and Ic: genotype phenotype relationship and evidence of the maternal transmission of the hormonal resistance. J Clin Endocrinol Metab. 2002;87(1): 189-197.

16. Luttikhuis ME, Wilson LC, Leonard JV, Trembath RC. Characterization of a de novo 43-bp deletion of the Gs alpha gene (GNAS1) in Albright hereditary osteodystrophy. Genomics. 1994;21(2):455-457.

17. Miric A, Vechio JD, Levine MA. Heterogeneous mutations in the gene encoding the alpha-subunit of the stimulatory G protein of adenylyl cyclase in Albright hereditary osteodystrophy. J Clin Endocrinol Metab. 1993;76(6):1560-1568.

18. Nakamoto JM, Sandstrom AT, Brickman AS, Christenson RA, Van Dop C. Pseudohypoparathyroidism type Ia from maternal but not paternal transmission of a Gsalpha gene mutation. Am J Med Genet. 1998;77(4): 261-267.

19. Nakamoto JM, Zimmerman D, Jones EA, et al. Concurrent hormone resistance (pseudohypoparathyroidism type Ia) and hormone independence (testotoxicosis) caused by a unique mutation in the G alpha s gene. Biochem Mol Med. 1996;58(1):18-24.

20. Patten JL, Johns DR, Valle D, et al. Mutation in the gene encoding the stimulatory G protein of adenylate cyclase in Albright's hereditary osteodystrophy. N Engl J Med. 1990;322(20):1412-1419.

21. Schwindinger WF, Miric A, Zimmerman D, Levine MA. A novel Gs alpha mutant in a patient with Albright hereditary osteodystrophy uncouples cell surface receptors from adenylyl cyclase. $J$ Biol Chem. 1994;269(41):25387-25391. 
22. Shapira H, Mouallem M, Shapiro MS, Weisman Y, Farfel Z. Pseudohypoparathyroidism type Ia: two new heterozygous frameshift mutations in exons 5 and 10 of the Gs alpha gene. Hum Genet. 1996; 97(1):73-75.

23. Walden U, Weissörtel R, Corria Z, et al. Stimulatory guanine nucleotide binding protein subunit 1 mutation in two siblings with pseudohypoparathyroidism type 1a and mother with pseudopseudohypoparathyroidism. Eur J Pediatr. 1999;158(3):200-203.

24. Warner DR, Gejman PV, Collins RM, Weinstein LS. A novel mutation adjacent to the switch III domain of G(S alpha) in a patient with pseudohypoparathyroidism. Mol Endocrinol. 1997;11(11):1718-1727.

25. Warner DR, Weng G, Yu S, Matalon R, Weinstein LS. A novel mutation in the switch 3 region of Gsalpha in a patient with Albright hereditary osteodystrophy impairs GDP binding and receptor activation. $J$ Biol Chem. 1998;273(37):23976-23983.

26. Weinstein LS, Gejman PV, de Mazancourt P, American N, Spiegel AM. A heterozygous 4-bp deletion mutation in the Gs alpha gene (GNAS1) in a patient with Albright hereditary osteodystrophy. Genomics. 1992;13(4):1319-1321.

27. Weinstein LS, Gejman PV, Friedman E, et al. Mutations of the Gs alpha-subunit gene in Albright hereditary osteodystrophy detected by denaturing gradient gel electrophoresis. Proc Natl Acad Sci U S A. 1990;87(21):8287-8290.

28. Wilson LC, Oude Luttikhuis ME, Clayton PT, Fraser WD, Trembath RC. Parental origin of Gs alpha gene mutations in Albright's hereditary osteodystrophy. J Med Genet. 1994;31(11):835-839.

29. Yokoyama M, Takeda K, Iyota K, Okabayashi T, Hashimoto K. A 4-base pair deletion mutation of Gs alpha gene in a Japanese patient with pseudohypoparathyroidism. J Endocrinol Invest. 1996;19(4): 236-241.

30. Yu D, Yu S, Schuster V, Kruse K, Clericuzio CL, Weinstein LS. Identification of two novel deletion mutations within the Gs alpha gene (GNAS1) in Albright hereditary osteodystrophy. J Clin Endocrinol Metab. 1999;84(9):3254-3259.

31. Yu S, Yu D, Hainline BE, et al. A deletion hot-spot in exon 7 of the Gs alpha gene (GNAS1) in patients with Albright hereditary osteodystrophy. Hum Mol Genet. 1995;4(10):2001-2002.

32. Baltoumas FA, Theodoropoulou MC, Hamodrakas SJ. Interactions of the $\alpha$-subunits of heterotrimeric G-proteins with GPCRs, effectors and RGS proteins: a critical review and analysis of interacting surfaces, conformational shifts, structural diversity and electrostatic potentials. J Struct Biol. 2013;182(3):209-218.

33. Oldham WM, Hamm HE. Heterotrimeric G protein activation by G-protein-coupled receptors. Nat Rev Mol Cell Biol. 2008;9(1):60-71.

34. Wettschureck N, Offermanns S. Mammalian G proteins and their cell type specific functions. Physiol Rev. 2005;85(4):1159-1204.

35. Heydorn A, Ward RJ, Jorgensen R, et al. Identification of a novel site within $\mathrm{G}$ protein alpha subunits important for specificity of receptor-G protein interaction. Mol Pharmacol. 2004;66(2):250-259.

36. McCudden CR, Hains MD, Kimple RJ, Siderovski DP, Willard FS. G-protein signaling: back to the future. Cell Mol Life Sci. 2005;62(5): 551-577.

37. Huang C, Hepler JR, Gilman AG, Mumby SM. Attenuation of Gi- and Gq-mediated signaling by expression of RGS4 or GAIP in mammalian cells. Proc Natl Acad Sci U S A. 1997;94(12):6159-6163.

38. Roy AA, Lemberg KE, Chidiac P. Recruitment of RGS2 and RGS4 to the plasma membrane by $\mathrm{G}$ proteins and receptors reflects functional interactions. Mol Pharmacol. 2003;64(3):587-593.

39. Zheng B, Ma YC, Ostrom RS, et al. RGS-PX1, a GAP for GalphaS and sorting nexin in vesicular trafficking. Science. 2001;294(5548): 1939-1942.

40. Bastepe M. The GNAS Locus: Quintessential Complex Gene Encoding Gsalpha, XLalphas, and other Imprinted Transcripts. Curr Genomics. 2007;8(6):398-414.

41. Plagge A, Kelsey G, Germain-Lee EL. Physiological functions of the imprinted Gnas locus and its protein variants Galpha(s) and XLalpha(s) in human and mouse. $J$ Endocrinol. 2008;196(2):193-214.
42. Ishikawa Y, Bianchi C, Nadal-Ginard B, Homcy CJ. Alternative promoter and 5' exon generate a novel Gs alpha mRNA. J Biol Chem. 1990;265(15):8458-8462.

43. Puzhko S, Goodyer CG, Kerachian MA, et al. Parathyroid hormone signaling via Gos is selectively inhibited by an $\mathrm{NH}(2)$-terminally truncated Gos: implications for pseudohypoparathyroidism. J Bone Miner Res. 2011;26(10):2473-2485.

44. Mantovani G, Bondioni S, Locatelli M, et al. Biallelic expression of the Gsalpha gene in human bone and adipose tissue. J Clin Endocrinol Metab. 2004;89(12):6316-6319.

45. Weinstein LS, Yu S, Warner DR, Liu J. Endocrine manifestations of stimulatory $\mathrm{G}$ protein alpha-subunit mutations and the role of genomic imprinting. Endocr Rev. 2001;22(5):675-705.

46. Chen M, Gavrilova O, Liu J, et al. Alternative Gnas gene products have opposite effects on glucose and lipid metabolism. Proc Natl Acad Sci USA. 2005;102(20):7386-7391.

47. Germain-Lee EL, Schwindinger W, Crane JL, et al. A mouse model of albright hereditary osteodystrophy generated by targeted disruption of exon 1 of the Gnas gene. Endocrinology. 2005;146(11): 4697-4709.

48. Turan S, Fernandez-Rebollo E, Aydin C, et al. Postnatal establishment of allelic Gos silencing as a plausible explanation for delayed onset of parathyroid hormone resistance owing to heterozygous Gos disruption. J Bone Miner Res. 2014;29(3):749-760.

49. Plagge A, Isles AR, Gordon E, et al. Imprinted Nesp55 influences behavioral reactivity to novel environments. Mol Cell Biol. 2005;25(8): 3019-3026.

50. Richard N, Molin A, Coudray N, Rault-Guillaume P, Jüppner H, Kottler ML. Paternal GNAS mutations lead to severe intrauterine growth retardation (IUGR) and provide evidence for a role of XL $\alpha$ s in fetal development. J Clin Endocrinol Metab. 2013;98(9):E1549-E1556.

51. Kobayashi NR, Hawes SM, Crook JM, Pébay A. G-protein coupled receptors in stem cell self-renewal and differentiation. Stem Cell Rev. 2010;6(3):351-366.

52. Pignolo RJ, Xu M, Russell E, et al. Heterozygous inactivation of Gnas in adipose-derived mesenchymal progenitor cells enhances osteoblast differentiation and promotes heterotopic ossification. $J$ Bone Miner Res. 2011;26(11):2647-2655.

53. Wu JY, Aarnisalo P, Bastepe M, et al. Gs $\alpha$ enhances commitment of mesenchymal progenitors to the osteoblast lineage but restrains osteoblast differentiation in mice. J Clin Invest. 2011;121(9):3492-3504.

54. Berdeaux R, Stewart R. cAMP signaling in skeletal muscle adaptation: hypertrophy, metabolism, and regeneration. Am J Physiol Endocrinol Metab. 2012;303(1):E1-E17.

55. Liu JJ, Russell E, Zhang D, Kaplan FS, Pignolo RJ, Shore EM. Paternally inherited gs $\alpha$ mutation impairs adipogenesis and potentiates a lean phenotype in vivo. Stem Cells. 2012;30(7):1477-1485.

56. Sinha P, Aarnisalo P, Chubb R, et al. Loss of Gs $\alpha$ early in the osteoblast lineage favors adipogenic differentiation of mesenchymal progenitors and committed osteoblast precursors. $J$ Bone Miner Res. 2014;29(11):2414-2426.

57. Sakamoto A, Chen M, Kobayashi T, Kronenberg HM, Weinstein LS. Chondrocyte-specific knockout of the G protein $G(s)$ alpha leads to epiphyseal and growth plate abnormalities and ectopic chondrocyte formation. J Bone Miner Res. 2005;20(4):663-671.

58. Doze VA, Perez DM. G-protein-coupled receptors in adult neurogenesis. Pharmacol Rev. 2012;64(3):645-675.

59. Huso DL, Edie S, Levine MA, et al. Heterotopic ossifications in a mouse model of albright hereditary osteodystrophy. PLOS ONE. 2011;6(6):e21755.

60. Gharibi B, Abraham AA, Ham J, Evans BA. Adenosine receptor subtype expression and activation influence the differentiation of mesenchymal stem cells to osteoblasts and adipocytes. $J$ Bone Miner Res. 2011;26(9):2112-2124.

61. Gharibi B, Abraham AA, Ham J, Evans BA. Contrasting effects of A1 and $A 2 b$ adenosine receptors on adipogenesis. Int J Obes. 2012;36(3): $397-406$. 
62. Bachman ES, Dhillon H, Zhang CY, et al. betaAR signaling required for diet-induced thermogenesis and obesity resistance. Science. 2002;297(5582):843-845.

63. Li H, Fong C, Chen Y, Cai G, Yang M. Beta-adrenergic signals regulate adipogenesis of mouse mesenchymal stem cells via cAMP/PKA pathway. Mol Cell Endocrinol. 2010;323(2):201-207.

64. Li H, Fong C, Chen Y, Cai G, Yang M. beta2- and beta3-, but not beta1-adrenergic receptors are involved in osteogenesis of mouse mesenchymal stem cells via cAMP/PKA signaling. Arch Biochem Biophys. 2010;496(2):77-83.

65. Torres B, Zambon AC, Insel PA. P2Y11 receptors activate adenylyl cyclase and contribute to nucleotide-promoted cAMP formation in MDCK-D(1) cells. A mechanism for nucleotide-mediated autocrineparacrine regulation. J Biol Chem. 2002;277(10):7761-7765.

66. Lee H, Jun DJ, Suh BC, et al. Dual roles of P2 purinergic receptors in insulin-stimulated leptin production and lipolysis in differentiated rat white adipocytes. J Biol Chem. 2005;280(31):28556-28563.

67. Regard JB, Malhotra D, Gvozdenovic-Jeremic J, et al. Activation of Hedgehog signaling by loss of GNAS causes heterotopic ossification. Nat Med. 2013;19(11):1505-1512.

68. Regard JB, Cherman N, Palmer D, et al. Wnt/ $\beta$-catenin signaling is differentially regulated by $\mathrm{G} \alpha$ proteins and contributes to fibrous dysplasia. Proc Natl Acad Sci U S A. 2011;108(50):20101-20106.

69. James AW. Review of Signaling Pathways Governing MSC Osteogenic and Adipogenic Differentiation. Scientifica (Cairo). 2013;2013:684736.

70. James AW, Leucht P, Levi B, et al. Sonic Hedgehog influences the balance of osteogenesis and adipogenesis in mouse adipose-derived stromal cells. Tissue Eng Part A. 2010;16(8):2605-2616.

71. Sheng T, Chi S, Zhang X, Xie J. Regulation of Gli1 localization by the cAMP/protein kinase A signaling axis through a site near the nuclear localization signal. J Biol Chem. 2006;281(1):9-12.

72. Epstein DJ, Marti E, Scott MP, McMahon AP. Antagonizing cAMPdependent protein kinase A in the dorsal CNS activates a conserved Sonic hedgehog signaling pathway. Development. 1996;122(9): 2885-2894.

73. Makinodan E, Marneros AG. Protein kinase A activation inhibits oncogenic Sonic hedgehog signalling and suppresses basal cell carcinoma of the skin. Exp Dermatol. 2012;21(11):847-852.

74. Tuson M, He M, Anderson KV. Protein kinase A acts at the basal body of the primary cilium to prevent Gli2 activation and ventralization of the mouse neural tube. Development. 2011;138(22):4921-4930.

75. Lian JB, Stein GS, Javed A, et al. Networks and hubs for the transcriptional control of osteoblastogenesis. Rev Endocr Metab Disord. 2006;7(1-2):1-16.

76. Matsubara T, Kida K, Yamaguchi A, et al. BMP2 regulates Osterix through Msx2 and Runx2 during osteoblast differentiation. J Biol Chem. 2008;283(43):29119-29125.

77. Zhang S, Kaplan FS, Shore EM. Different roles of GNAS and cAMP signaling during early and late stages of osteogenic differentiation. Horm Metab Res. 2012;44(10):724-731.

78. Lemos MC, Thakker RV. GNAS mutations in pseudohypoparathyroidism type 1a and related disorders. Hum Mutat. Epub September 13, 2014.

79. Lebrun M, Richard N, Abeguilé G, et al. Progressive osseous heteroplasia: a model for the imprinting effects of GNAS inactivating mutations in humans. J Clin Endocrinol Metab. 2010;95(6):3028-3038.

80. Elli FM, Barbieri AM, Bordogna P, et al. Screening for GNAS genetic and epigenetic alterations in progressive osseous heteroplasia: first Italian series. Bone. 2013;56(2):276-280.
81. Cairns DM, Pignolo RJ, Uchimura T, et al. Somitic disruption of GNAS in chick embryos mimics progressive osseous heteroplasia. J Clin Invest. 2013;123(8):3624-3633.

82. Kaplan FS, Shore EM. Progressive osseous heteroplasia. J Bone Miner Res. 2000;15(11):2084-2094.

83. Shore EM, Xu M, Feldman GJ, et al. A recurrent mutation in the BMP type I receptor ACVR1 causes inherited and sporadic fibrodysplasia ossificans progressiva. Nat Genet. 2006;38(5):525-527.

84. Bastepe M, Fröhlich LF, Linglart A, et al. Deletion of the NESP55 differentially methylated region causes loss of maternal GNAS imprints and pseudohypoparathyroidism type Ib. Nat Genet. 2005;37(1): 25-27.

85. Jüppner H, Schipani E, Bastepe $M$, et al. The gene responsible for pseudohypoparathyroidism type $\mathrm{Ib}$ is paternally imprinted and maps in four unrelated kindreds to chromosome 20q13.3. Proc Natl Acad Sci US A. 1998;95(20):11798-11803.

86. Ruggieri M, Pavone V, Polizzi A, et al. Familial osteoma of the cranial vault. Br J Radiol. 1998;71(842):225-228.

87. Athanasou NA, Benson MK, Brenton BP, Smith R. Progressive osseous heteroplasia: a case report. Bone. 1994;15(5):471-475.

88. Rosenfeld SR, Kaplan FS. Progressive osseous heteroplasia in male patients. Two new case reports. Clin Orthop Relat Res. 1995;(317): 243-245.

89. Schmidt AH, Vincent KA, Aiona MD. Hemimelic progressive osseous heteroplasia. A case report. J Bone Joint Surg Am. 1994;76(6): 907-912.

90. Urtizberea JA, Testart H, Cartault F, Boccon-Gibod L, Le Merrer M, Kaplan FS. Progressive osseous heteroplasia. Report of a family. J Bone Joint Surg Br. 1998;80(5):768-771.

91. Long DN, McGuire S, Levine MA, Weinstein LS, Germain-Lee EL. Body mass index differences in pseudohypoparathyroidism type 1a versus pseudopseudohypoparathyroidism may implicate paternal imprinting of Galpha(s) in the development of human obesity. J Clin Endocrinol Metab. 2007;92(3):1073-1079.

92. Eddy MC, Jan De Beur SM, Yandow SM, et al. Deficiency of the alpha-subunit of the stimulatory $\mathrm{G}$ protein and severe extraskeletal ossification. J Bone Miner Res. 2000;15(11):2074-2083.

93. Tresserra L, Tresserra F, Grases PJ, Badosa J, Tresserra M. Congenital plate-like osteoma cutis of the forehead: an atypical presentation form. J Craniomaxillofac Surg. 1998;26(2):102-106.

94. Yeh GL, Mathur S, Wivel A, et al. GNAS1 mutation and Cbfa1 misexpression in a child with severe congenital platelike osteoma cutis. J Bone Miner Res. 2000;15(11):2063-2073.

95. Aynaci O, Müjgan Aynaci F, Cobanoğlu U, Alpay K. Progressive osseous heteroplasia. A case report and review of the literature. J Pediatr Orthop B. 2002;11(4):339-342.

96. Hou JW. Progressive osseous heteroplasia controlled by intravenous administration of pamidronate. Am J Med Genet A. 2006;140(8): 910-913.

97. Trinh TN, McLaughlin EA, Gordon CP, McCluskey A. Hedgehog signalling pathway inhibitors as cancer suppressing agents. Med Chem Comm. 2014;5(2):117-133.

98. Shimono K, Tung WE, Macolino C, et al. Potent inhibition of heterotopic ossification by nuclear retinoic acid receptor- $\gamma$ agonists. Nat Med. 2011;17(4):454-460.

99. Chan SD, Strewler GJ, Nissenson RA. Transcriptional activation of Gs alpha expression by retinoic acid and parathyroid hormone-related protein in F9 teratocarcinoma cells. J Biol Chem. 1990;265(33): 20081-20084. 
The Application of Clinical Genetics

Dovepress

\section{Publish your work in this journal}

The Application of Clinical Genetics is an international, peer-reviewed open access journal that welcomes laboratory and clinical findings in the field of human genetics. Specific topics include: Population genetics; Functional genetics; Natural history of genetic disease; Management of genetic disease; Mechanisms of genetic disease; Counseling and ethical

issues; Animal models; Pharmacogenetics; Prenatal diagnosis; Dysmorphology. The manuscript management system is completely online and includes a very quick and fair peer-review system, which is all easy to use. Visit http://www.dovepress.com/testimonials.php to read real quotes from published authors.

Submit your manuscript here: http://www.dovepress.com/the-application-of-clinical-genetics-journal 